\title{
Update on the evaluation of transient vision loss
}

This article was published in the following Dove Press journal:

Clinical Ophthalmology

I I February 2016

Number of times this article has been viewed

\author{
John H Pula' \\ Katherine Kwan ${ }^{2}$ \\ Carlen A Yuen ${ }^{3}$ \\ Jorge C Kattah ${ }^{4}$ \\ 'Department of Neurology, \\ ${ }^{2}$ Department of ophthalmology, \\ NorthShore University HealthSystem, \\ Evanston IL, USA; ${ }^{3}$ University of \\ Illinois College of Medicine at Peoria, \\ ${ }^{4}$ Department of Neurology, University \\ of Illinois College of Medicine at \\ Peoria, Peoria, IL, USA
}

\begin{abstract}
Transient vision loss may indicate underlying vascular disease, including carotid occlusion and thromboembolism, or it may have a more benign etiology, such as migraine or vasospasm. This review focuses on the differential diagnosis and workup of patients presenting with transient vision loss, focusing on several key areas: the relationship to thromboembolic vascular disease, hypercoagulable testing, retinal migraine, and bilateral vision loss. The objective is to provide the ophthalmologist with information on how to best manage these patients. Thromboembolic etiologies for transient vision loss are sometimes managed with medications, but when carotid surgery is indicated, earlier intervention may prevent future stroke. This need for early treatment places the ophthalmologist in the important role of expediting the management process. Hospital admission is recommended in patients presenting with transient symptoms within 72 hours who meet certain high-risk criteria. When the cause is giant cell arteritis, ocular ischemic syndrome, or a cardioembolic source, early management of the underlying condition is equally important. For nonthromboembolic causes of transient vision loss such as retinal migraine or retinal vasospasm, the ophthalmologist can provide reassurance as well as potentially give medications to decrease the frequency of vision loss episodes.
\end{abstract}

Keywords: transient vision loss, TVL, amaurosis fugax, retinal migraine, ocular migraine, retinal vasospasm

\section{Introduction}

A proper, well-performed history and physical exam after an episode of transient vision loss (TVL) improves the chance of finding its cause. Determining the etiology of TVL will guide management. This is why there is no "cookie-cutter" algorithm which fits all patients with TVL. TVL is a symptom of some underlying pathophysiologic problem, and so management depends on finding the cause that precipitated it.

TVL is not always interchangeable with "amaurosis fugax". Most ophthalmologists use the term amaurosis fugax when they suspect a thromboembolic vascular etiology as the cause of monocular TVL. ${ }^{1}$ Amaurosis fugax comes from a combination of the Greek terms "amauroun" (to darken) and the Latin "fugax" (fleeting). Because many patients present to an ophthalmologist with TVL as the harbinger of cerebrovascular disease ${ }^{2}$ it is important to be aware of their future potential for stroke, but not pigeonhole all TVL into amaurosis fugax. Table 1 lists the major causes to consider when a patient presents with TVL.

\section{Methodology}

We conducted a search using the PubMed database up to November 28, 2015. Reference lists were used to obtain additional studies as warranted. Search keywords included "amaurosis fugax", "transient monocular vision loss", "transient monocular blindness", and "transient vision loss", with special interest given for publications dated later than 2013. We focused the review on several topics of key interest: the
Correspondence: John H Pula Department of Neurology, NorthShore University HealthSystem, 2650 Ridge

Ave, Evanston, IL 6020I, USA

Tel +l 8475702000

Fax +I 8475703500

Email jpula I2004@yahoo.com
Clinical Ophthalmology 2016:10 297-303

(c) (1) (2) ( 2016 Pula et al. This work is published and licensed by Dove Medical Press Limited. The full terms of this license are avalable at https://www.dovepress.com/terms.php cc) hereby accept the Terms. Non-commercial uses of the work are permitted without any further permission from Dove Medical Press Limited, provided the work is properly atributed. For peminsion for commercial use of this work, please see paragraphs 4.2 and 5 of our Terms (https://www.doveppess. com/terms.php).

297
Dovepress

http://dx.doi.org/10.2147/OPTH.S9497। 
Table I Categories of transient vision loss

\begin{tabular}{ll}
\hline Location & Causes of transient vision loss \\
\hline Monocular & Vascular - embolic \\
& Vascular - thrombotic (giant cell arteritis) \\
& Vascular - stenotic \\
& Vasospasm \\
& Retinal migraine \\
& Ocular - closed angles, hyphema \\
Binocular & Vascular - thromboembolic \\
& Occipital epilepsy \\
& Complex migraine \\
Monocular & Papilledema or optic disc disease \\
or binocular & (transient visual obscurations) \\
& Uhthoff phenomena
\end{tabular}

Notes: Monocular and binocular vision losses have overlapping and specific causes. Transient visual obscurations and Uhthoff phenomena are also important causes of transient vision loss, but the context of these is distinct enough from the others that we will not be highlighting them in this review.

relationship of TVL to thromboembolic vascular disease, hypercoagulable testing, retinal migraine, and bilateral vision loss.

\section{Obtaining a history in patients with TVL}

Certain information about pattern, timing, provoking factors, and associated symptoms will provide clues to the etiology of TVL. Obtaining this information will improve the yield and efficiency of ordering further diagnostic tests.

The pattern of visual field loss during an episode of TVL provides prognostic information. Patients with altitudinal TVL are more likely to have a carotid or cardiac embolic source compared to patients with diffuse or constricting patterns of vision loss. ${ }^{3}$ Altitudinal TVL increases the odds of internal carotid artery stenosis by $3.5 .{ }^{4,5}$ More specifically, altitudinal onset of TVL yields an odds ratio for carotid disease of 4.1; altitudinal disappearance yields an odds ratio of 2.7 .4 Since $\sim 40 \%$ of patients with an altitudinal defect at the start of TVL progress to a diffuse or total vision loss, ${ }^{3}$ it is important to specifically ask about how the TVL was perceived at its onset. A smaller percentage of patients have a vertical hemifield TVL. ${ }^{3}$

In contrast, characteristics of the TVL are less helpful in predicting the nature of future ocular vascular events. No differences in the character of field defects during a TVL differentiate whether a patient will later develop a central retinal artery occlusion (CRAO), retinal vein occlusion, nonarteritic anterior ischemic optic neuropathy, or giant cell arteritis (GCA). There is also no correlation between time lapse from the TVL to when permanent vision loss would occur and the cause of the permanent vision loss. ${ }^{6}$ Timing and
Table 2 Patient history of transient vision loss

\begin{tabular}{l} 
Questions to ask regarding transient vision loss \\
\hline Monocular or binocular \\
Duration and timing of vision loss \\
Provoking factors (positional change, sexual activity) \\
Associated symptoms (giant cell arteritis ROS, migraine headaches) \\
Pattern of vision loss (altitudinal versus diffuse/constricting) \\
Retinal claudication \\
Recent ocular surgery or cerebral angiography \\
History of atrial fibrillation or thromboembolic disease
\end{tabular}

Notes: Certain questions may have added importance in the patient with transient vision loss. The answers can direct and focus ancillary testing to determine etiology. Abbreviation: ROS, review of systems.

duration of TVL do provide some information, however: patients with TVL lasting 1-10 minutes are more likely to have carotid stenosis. ${ }^{5}$ Retinal claudication is one historical feature predicting complete carotid occlusion. Dimming of vision in one eye after exposure to bright light after TVL has an odds ratio of 4.8 for finding $100 \%$ ipsilateral carotid occlusion. ${ }^{5}$ Even if the patient is not able to recall much history, this "lack" of information itself may be helpful: patients unable to remember details of their TVL are more likely to have normal carotid arteries. ${ }^{5}$

Recent ophthalmologic history and a thorough ocular exam also provide important prognostic clues for TVL. There is a subset of patients who have posturally-induced TVL and increased intraocular pressure after vitrectomy or retinal detachment repair. ${ }^{7}$ Because none in the cohort developed cardiovascular complications, this may be a subgroup of TVL not requiring extensive cardioembolic evaluation. TVL due to nonembolic causes can occur after exercise, long-distance running, or sexual intercourse. ${ }^{8-10}$ The mechanism is probably vasospasm, although evaluation of one man whose symptoms occurred during orgasm revealed closed angles, ${ }^{10}$ an ocular cause of TVL.

Table 2 summarizes historical information important to obtain in a patient with TVL.

\section{TVL and thromboembolic vascular disease General considerations}

Public awareness that TVL could be a transient ischemic attack (TIA) is low: between $7 \%$ and $44 \%{ }^{11,12}$ This compares to $80 \%-90 \%$ of people who recognize that speech, face, and arm symptoms are associated with stroke. ${ }^{13}$ Compared to other TIA symptoms, patients with TVL arrive less quickly to the emergency room. ${ }^{14}$ Time to referral and time to carotid ultrasound for patients with nonvisual TIA are 10 days and 30 days, respectively, compared to 16 and 46 days for patients 
with TVL. ${ }^{15}$ Time to carotid endarterectomy (CEA) is 69 days for cortical-type TIA and 103 days for TVL. ${ }^{16}$

Regarding the incidence of TVL in TIA, one study examined 2,398 patients with suspected TIA over 5 years. In all, 826 (34.5\%) reported transient visual symptoms and $422(17.6 \%)$ had "only" visual symptoms. Of these, $36.3 \%$ had TVL, $12.3 \%$ transient hemianopia, $10.8 \%$ bilateral positive visual phenomena, and $4.5 \%$ bilateral total vision loss. ${ }^{17}$ A study from Japan of 444 patients admitted to a TIA center reported $2.9 \%$ presenting as TVL. ${ }^{14}$ What is the incidence of carotid disease in patients with TVL? Of 337 patients with transient monocular vision loss studied prospectively, 159 had a normal internal carotid artery patency, 33 had $0 \%-69 \%$ stenosis, 100 had $70 \%-99 \%$ stenosis, and 45 had $100 \% .^{5}$

\section{Carotid disease}

Both the North American Symptomatic Carotid Endarterectomy Trial (NASCET) and the European Carotid Surgery Trial established that early surgery (within 14 days) reduces risk of stroke in TIA patients with carotid disease. ${ }^{18,19}$ The highest risk period for stroke after TIA is within the first 7 days. ${ }^{20}$ Performing a CEA within 2 weeks in 1,000 TIA patients would prevent 185 strokes in 5 years, compared to only eight strokes if performed after 12 weeks. ${ }^{21}$ Only $19 \%$ of ophthalmologists are aware of this 2 -week time window. ${ }^{20}$

However, NASCET also found that there is a relatively decreased stroke risk in TVL versus other types of TIA. ${ }^{22}$ Since risk is lower, it has been suggested that for TVL, surgical treatment of carotid disease be restricted to patients with only certain features (Table 3 ) ${ }^{23}$ Carotid surgery in patients with two versus three of these risk factors improves 3-year stroke risk reduction from 4.9 to 14.3. Retinal microaneurysms, cotton wool spots, flame or blot retinal hemorrhages, and arteriovenous nicking on exam after TVL also increase stroke risk in patients with TVL, by a factor of $3 .^{24}$

Table 3 Treatment of carotid disease after transient vision loss

\begin{tabular}{ll}
\hline Present & Three of the following other risk factors \\
\hline$>70 \%$ carotid stenosis & Male sex \\
& Lack of collaterals on angiogram \\
& Hemispheric transient ischemic attack (TIA) \\
& Peripheral vascular disease \\
& $80 \%-94 \%$ carotid stenosis \\
& Age $>75$ \\
\hline
\end{tabular}

Note: Because the North American Symptomatic Carotid Endarterectomy Trial noted a decreased risk of stroke after transient vision loss compared to other TIA presentations, it has been suggested that surgical treatment of carotid disease be restricted to patients with only a certain subset of risk factors listed here.
Twenty percent of all CEAs are performed for TVL. ${ }^{25}$ Carotid artery plaques have less MMP-8, MMP-9, and interleukin-8 in patients with TVL, suggesting a less atheromatous and more collagen-rich substrate. ${ }^{26}$ Timely evaluation and early intervention are the most important variables for the ophthalmologist to recognize TVL caused by carotid disease.

\section{Retinal artery occlusion}

CRAO shares pathophysiologic similarities to stroke, and TVL can be a precursor to both branch retinal artery occlusion (BRAO) and central CRAO. ${ }^{27}$ The prevalence of TVL prior to CRAO is $12.2 \%$, and BRAO is $15.4 \% .{ }^{6}$ Besides emboli, TVL prior to CRAO could be caused by decreased perfusion pressure due to fall in arterial pressure from comorbid carotid disease or orthostasis, vasospasm, or rise in intraocular pressure. ${ }^{6,28}$ Because it is difficult to predict which cases of TVL will progress to CRAO, ${ }^{6}$ management focuses on the diagnostic evaluation and determining the embolic source.

\section{Ocular ischemic syndrome}

Carotid disease can produce ocular ischemic syndrome. TVL can occur in ocular ischemic syndrome when bright light saturates the retina. There is often associated dull pain. This light-induced amaurosis may result from failure to regenerate visual pigment due to underlying degenerative changes of the retina from chronic ischemia. ${ }^{29}$ If TVL is found to be related to ocular ischemic syndrome, management is based on treating the cause of the ischemia, which is often due to severe carotid stenosis.

\section{Cardiac causes}

Although most literature on TVL focuses on carotid artery disease, emboli can originate from atrial fibrillation, valvular disease, and other sources from the heart, including mobile masses. ${ }^{30}$ Management of the TVL when by a cardiac cause is also then dependent on the specific cardiac problem. Recognizing that thromboembolic TVL is not always carotid in origin should prompt evaluation with echocardiogram and electrocardiogram.

\section{Giant cell arteritis}

GCA can cause TVL. Fluorescein angiography during an episode of TVL from GCA may show total occlusion of retinal circulation followed by reperfusion..$^{31}$ The prevalence of TVL in GCA is $32.4 \%$, and the mechanism may be a slight rise in the intraocular pressure (even from rubbing the eyes) 
in the setting of a thrombosing posterior ciliary artery which compromises optic nerve blood flow. ${ }^{6}$ One 62-yearold woman was diagnosed with GCA after having painful TVL on awakening. C-reactive protein and sedimentation rates were elevated, and although fundus exam was normal, fluorescein angiography showed delayed and sluggish filling of retinal arterioles, probably due to reversible thrombotic occlusion or retinal vasospasm. ${ }^{32}$ Management of TVL when caused by GCA is based on proper diagnosis and treatment of the arteritis itself.

\section{Retinal artery stenosis}

Approximately $2 \%$ of TVL may be due to focal arterial stenosis distal to branching off the internal carotid artery. ${ }^{33}$ Cerebral angiography may show focal stenosis at the origin of the central retinal artery or ophthalmic artery. ${ }^{34}$ Viewing the fundus during symptomatic episodes in these cases reveals arteriolar constriction without emboli, and TVL can occur with bending the head down, suggesting hemodynamic change rather than emboli. Treatment with aspirin or calcium channel blockers decreases symptoms, possibly by reducing platelet activation and vasospasm. ${ }^{35}$

\section{TVL and hypercoagulable states}

The role of hypercoagulable states as a cause of TVL is unknown. Hypercoagulability can be caused by acquired or inherited coagulation disorders. A list of common inherited disorders is listed in Table 4. Acquired prothrombotic risk factors include immobilization, smoking, and hyperestrogenemia due to pregnancy or exogenous estrogen use. ${ }^{36,37}$ Although anticoagulation for inherited hypercoagulability may prevent vascular occlusions, ${ }^{36-38}$ a number of recent reviews from the stroke literature have found no correlation

Table 4 Hereditable thrombophilias

\begin{tabular}{ll}
\hline Thrombophilia & Mechanism causing hypercoagulability \\
\hline $\begin{array}{l}\text { Methylene } \\
\text { tetrahydrofolate }\end{array}$ & $\begin{array}{l}\text { Causes an increase in homocysteine, an } \\
\text { amino acid intermediate in the metabolism of } \\
\text { reductase mutation }\end{array}$ \\
$\begin{array}{l}\text { methionine which is linked to thrombosis } \\
\text { deficiency }\end{array}$ & $\begin{array}{l}\text { Protein S is a cofactor for protein C, which is a } \\
\text { proteolysis enzyme of factor Va and VIIla }\end{array}$ \\
Antithrombin III & $\begin{array}{l}\text { Antithrombin III is a protease for most clotting } \\
\text { feficiency }\end{array}$ \\
Factor V Leiden & $\begin{array}{l}\text { The mutation results in an increase in the } \\
\text { mutation }\end{array}$ \\
function of factor V, causing protein C to \\
function improperly \\
G202I0A mutation
\end{tabular}

Note: Both the mutation or deficiency and the mechanism causing hypercoagulability are listed here for the most commonly tested hereditable thrombophilias. between most hypercoagulable states and acute ischemic stroke, and state that there is no indication either for screening or for anticoagulation even if testing is positive. ${ }^{39}$

Indications for thrombophilia testing after TVL should focus on patients with recurrent TVL, or patients with a personal or family history of thrombotic events. Of the inherited thrombophilias, only factor V Leiden was found to have an elevated odds ratio (1.99) for amaurosis fugax and TIA, but only lupus anticoagulant had an increased odds ratio (2.66) for ischemic stroke. ${ }^{40}$ Because hyperhomocysteinemia is reversible, testing for serum levels may be beneficial. One study including patients with TVL demonstrated $100 \%$ normalization of serum homocysteine levels after a median follow-up of 21 months after treatment with folic acid, vitamin $B_{6}$, and vitamin $\mathrm{B}_{12} \cdot{ }^{36}$ There is no high-level evidence to guide treatment for thrombophilia in the setting of TVL, however, because antiphospholipid antibodies have the highest risk of stroke, and homocysteine can be treated relatively easily with a folate- $\mathrm{B}_{6}-\mathrm{B}_{12}$ combination; ${ }^{38,39}$ these two tests are probably the most appropriate to order in typical TVL. On the other hand, patients with recurrent cryptogenic TVL and other thrombotic history may need a complete hypercoagulable workup, and could require anticoagulation.

\section{TVL and retinal migraine}

The International Headache Society defines retinal migraine as reversible monocular vision loss in the setting of a typical migraine. ${ }^{41,42}$ Migraine should occur within 60 minutes of the vision loss. ${ }^{43}$ Under this definition, retinal migraine is not as common as some would think, ${ }^{44}$ as most cases in the literature purporting to describe retinal migraine do not fulfill this description. Among 60 articles with 142 patients reported, only 16 fit the International Headache Society criteria. ${ }^{43}$ Retinal migraine is referred to by numerous other terms, including visual migraine, eye migraine, and anterior visual pathway migraine, but it should not be confused with classic visual auras (cortical-based visual phenomena), ophthalmoplegic migraine (resulting in diplopia), or silent migraine (aura without headache).

What then is the actual cause for those cases of TVL previously thought to be retinal migraine? Although it may be tempting to suggest these episodes represent spreading depression of Leão, homologous to cortical migrainous phenomena, there is no evidence that spreading depression occurs in the human retina. ${ }^{43}$ The answer appears to be retinal vasospasm. ${ }^{43}$ Vasospasm can be precipitated by emotional stress, cold, or exercising. ${ }^{45}$ Examination during an episode of retinal migraine or vasospasm may show an afferent pupil 
defect and venous boxcarring, denoting decreased arterial perfusion. Vasospasm can occur in the cervical portion of the left internal carotid artery, which diminishes blood flow to the ophthalmic artery. ${ }^{46}$ Fluorescein angiography may show choroid blush and delayed central retinal artery circulation, with resolution of all abnormalities once the episode resolves.

In a 12-year retrospective study of 77 patients with nonembolic TVL, only $18 \%$ had a past or family history of migraine, and only $15 \%$ had headaches. Both retinal vasospasm and migraine are more frequent in women of childbearing age. ${ }^{47}$ That being said, the female preponderance in retinal migraine is only $1.4: 1$ compared to $3: 1$ for migraine. ${ }^{48}$

Regarding management, calcium channel blockers have shown efficacy. Even in patients with low blood pressure, low doses of calcium channel blocker may still be tolerated (eg, nifedipine 10-20 mg/day). ${ }^{49}$ Triptans, ergots, and beta blockers are best not used in migraine patients with TVL, due to concern for exacerbating vasoconstriction, ${ }^{50}$ especially since TVL in retinal migraine has been associated with later onset of permanent vision loss from occlusive conditions like CRAO and BRAO. ${ }^{48}$

\section{Binocular TVL}

It is important to determine if TVL is monocular or binocular. Because patients often fail to notice a deficit in binocular, this may be challenging. Often patients will not notice the nasal deficit, and focus only on the side of the temporal loss, assuming for example that a left hemianopia was actually left monocular visual loss. Transient binocular (cortical) vision loss may have similar causes as transient monocular vision loss (eg, thromboembolic, migraine) or have other causes, including epileptic seizures from the occipital cortex. ${ }^{51}$

Transient cortical blindness can occur during cerebral angiography, with incidence of $0.3 \%-1 \%,{ }^{52}$ most commonly during vertebral artery angiography. Vision loss may last for 24 hours. The mechanism may be a posterior reversible encephalopathy-like syndrome, but there is some evidence that the cause is a neurotoxic effect from contrast..$^{53}$ Resolution with time is the rule.

The prevalence of episodic binocular blindness in migraine patients is $1.6 \%$, lasting from seconds to 120 minutes. ${ }^{54} \mathrm{We}$ treated one patient with a 20 -year history of minutes-long transient homonymous hemianopia associated with her migraines. One of the episodes of hemianopia was otherwise typical except it persisted after 3 days. Magnetic resonance imaging (MRI) showed restricted diffusion in the associated visual cortex. Embolic workup was negative, and her field defect resolved after 2 weeks.
Though most literature regarding thromboembolism is focused on monocular vision loss, transient homonymous hemianopia is also an important warning sign of stroke. TIAs are actually more common prior to vertebrobasilar stroke than anterior circulation stroke (odds ratio 2.92). ${ }^{55}$ Furthermore, the most common TIA in vertebrobasilar stenosis is binocular vision disturbance. ${ }^{55}$ Management in these cases is similar to that of suspected anterior circulation ischemia.

\section{Acute management of TVL}

When TVL is suspected to be caused by thromboembolism, what is the workup? Regarding timing and location of workup, different communities have their own limitations in resources. That being said, there are some data to help guide recommendations. If presentation is within 72 hours, the American Heart Association recommends admission to a hospital setting when age, blood pressure, clinical features, and duration of symptoms (ABCD) score is 3, or for ABCD score of 2 with either uncertainty that outpatient treatments will be done or other evidence of an embolic source. ${ }^{56}$ For presentation between 3 and 7 days, hospitalization is still recommended if the patient already had a known untreated source of ischemia (carotid stenosis, atrial fibrillation). ${ }^{57}$ Regarding workup, the most important tests are those which could change management based on finding an active embolic source. This includes large vessel vascular imaging (computed tomography angiogram/magnetic resonance angiogram head/neck, or carotid Doppler for monocular vision loss) and cardiac evaluation (electrocardiogram, echocardiogram). Some sources recommend brain imaging as part of the TVL workup. ${ }^{56,58}$ One study looked at 213 consecutive patients with BRAO, CRAO, or amaurosis fugax. In all, 23\% of patients were found to have infarctions on MRI, most of them asymptomatic. ${ }^{59}$ However, it is unclear if brain imaging adds information which would change management assuming an otherwise complete vascular workup is performed. There are no clear-cut guidelines regarding when or if to order many of the other ancillary tests discussed earlier (orbital ultrasound, hypercoagulable serum markers, electroencephalogram, etc), but this is why the history and physical examination are so important as they guide the clinician to other appropriate tests.

\section{Conclusion}

Managing TVL begins with a focused history and examination. Once a preliminary diagnosis is made, evaluation and treatment depend on the findings. Amaurosis fugax requires workup with carotid and cardiac imaging. 
Hypercoagulable testing and angiography may be helpful in certain cases. Carotid surgery or antithrombotic medications (antiplatelet/anticoagulation) can prevent future stroke. Retinal vasospasm could be treated with aspirin or calcium channel blockers. Retinal migraine responds to standard migraine treatments. Ocular causes such angle closure are treated accordingly. First and foremost, however, the patient must get evaluated. Therefore, we must continue to educate the public and our medical colleagues about the importance of getting an ophthalmologic evaluation in patients with TVL.

\section{Acknowledgment}

The authors wish to thank the OSF Peoria Medical Center Library for their assistance in acquiring references.

\section{Disclosure}

The authors report no conflicts of interest in this work.

\section{References}

1. Petzold A, Islam N, Hu H-H, Plant GT. Embolic and nonembolic transient monocular visual field loss: a clinicopathologic review. Surv Ophthalmol. 2013;58(1):42-62.

2. Lawlor M, Perry R, Hunt BJ, Plant GT. Strokes and vision: the management of ischemic arterial disease affecting the retina and occipital lobe. Surv Ophthalmol. 2015;60(4):296-309.

3. Bruno A, Corbett JJ, Biller J, Adams HP Jr, Qualls C. Transient monocular visual loss patterns and associated vascular abnormalities. Stroke. 1990;21(1):34-39.

4. Donders RC; Dutch TMB Study Group. Clinical features of transient monocular blindness and the likelihood of atherosclerotic lesions of the internal carotid artery. J Neurol Neurosurg Psychiatry. 2001;71(2): 247-249.

5. Bagheri N, Mehta S. Acute vision loss. Prim Care. 2015;42(3): 347-361.

6. Hayreh SS, Zimmerman MB. Amaurosis fugax in ocular vascular occlusive disorders: prevalence and pathogeneses. Retina. 2014;34(1): $115-122$.

7. Subramanian PS. How urgent is the treatment of transient vision loss? Br J Ophthalmol. 2014;98(6):719-720.

8. Petzold A, Islam N, Plant GT. Patterns of non-embolic transient monocular visual field loss. J Neurol. 2013;260(7):1889-1900.

9. Kofoed PK, Milea D, Larsen M. Transient monocular blindness precipitated by sexual intercourse. Br J Ophthalmol. 2009;93(9): 1199.

10. Lee MD, Odel JG, Rudich DS, Ritch R. Vision loss with sexual activity. J Glaucoma. Epub 2014 Sep 26:25265010.

11. Pancioli AM, Broderick J, Kothari R, et al. Public perception of stroke warning signs and knowledge of potential risk factors. JAMA. 1998; 279(16):1288-1292.

12. Sug Yoon S, Heller RF, Levi C, Wiggers J, Fitzgerald PE. Knowledge of stroke risk factors, warning symptoms, and treatment among an Australian urban population. Stroke. 2001;32(8):1926-1930.

13. Robinson TG, Reid A, Haunton VJ, Wilson A, Naylor AR. The face arm speech test: does it encourage rapid recognition of important stroke warning symptoms? Emerg Med J. 2013;30(6):467-471.

14. Tanaka K, Uehara T, Kimura K, et al; Japan TIA Research Group 2009-2011. Features of patients with transient monocular blindness: a multicenter retrospective study in Japan. J Stroke Cerebrovasc Dis. 2014;23(3):e151-e155.
15. Fairhead JF, Mehta Z, Rothwell PM. Population based study of delays in carotid imaging and surgery and the risk of recurrent stroke. Neurology. 2005;65(3):371-375.

16. Jetty P, Husereau D, Kubelik D, et al. Wait times among patients with symptomatic carotid artery stenosis requiring carotid endarterectomy for stroke prevention. J Vasc Surg. 2012;56(3):661-667.

17. Lavallée PC, Cabrejo L, Labreuche J, et al. Spectrum of transient visual symptoms in a transient ischemic attack cohort. Stroke. 2013;44(12): 3312-3317.

18. Rothwell PM, Eliasziw M, Gutnikov SA, Warlow CP, Barnett HJ; Carotid Endarterectomy Trialists Collaboration. Endarterectomy for symptomatic carotid stenosis in relation to clinical subgroups and timing of surgery. Lancet. 2004;363(941):915-924.

19. Kulkami SR, Gohel MS, Bulbulia RA, Whyman MR, Poskitt KR. The importance of early carotid endarterectomy in symptomatic patients. Ann R Coll Surg Engl. 2009;91(3):210-213.

20. Naylor AR, Robinson TG, Eveson D, Burns J. An audit of management practices in patients with suspected temporary monocular blindness. Br J Ophthalmol. 2014;98(6):730-733.

21. Naylor AR. Time is brain! Surgeon. 2007;51:23-30.

22. Ferguson GG, Eliasziw M, Barr HW, et al. The North American Symptomatic Carotid Endarterectomy Trial. Stroke. 1999;309:1751-1758.

23. Benavente O, Eliasziw M, Streifler JY, et al. Prognosis after transient monocular blindness associated with carotid-artery stenosis. $\mathrm{N} \mathrm{Engl} \mathrm{J}$ Med. 2001;345(15):1084-1090.

24. Wong TY, Klein R, Couper DJ, et al. Retinal microvascular abnormalities and incident stroke: the Atherosclerosis Risk in Communities Study. Lancet. 2001;358(9288):1134-1140.

25. UK Carotid Endarterectomy Audit: Round 4 Public Report (01.10. 10-30.09.12). Available from: http://www.vascularsociety.org. Accessed April 2, 2013.

26. Cheung N, Klein R, Wang JJ, et al. Traditional and novel cardiovascular risk factors for retinal vein occlusion: the multiethnic study of atherosclerosis. Invest Ophthalmol Vis Sci. 2008;49(10):4297-4302.

27. Georgalas I, Koutsandrea C. Images in clinical medicine. Amaurosis Fugax Caused by a Branch Retinal Artery Embolus. $N$ Engl $J$ Med. 2015;373(22):e26.

28. Shah RP, Menzoian JO. Sleep-induced amaurosis fugax. J Vasc Surg. 2011;54(5):1492-1494.

29. Shin YW, Kim JM, Jung KH, et al. Light-induced amaurosis fugax due to severe distal internal carotid artery stenosis: in view of managing ocular ischemic syndrome. J Neurol. 2013;260(6):1655-1657.

30. Mehrzad R, Bajaj R. A rare but important differential diagnosis in transient monocular blindness. BMJ Case Rep. 2014;2014.

31. Alwitry A. Regarding 'transient visual loss due to reversible 'pending' central retinal artery occlusion in occult giant cell arteritis'. Eye (Lond). 2015;29(8):1111. doi:10.1038/eye.2015.55.

32. Sane M, Selvadurai A, Reidy J, Higgs D, Gonzalez-Fernandez F, Lincoff N. Transient visual loss due to reversible 'pending' central retinal artery occlusion in occult giant cell arteritis. Eye (Lond). 2014; 28(11):1387-1390.

33. Adams HP, Putman SF, Corbett JJ, Sires BP, Thompson HS. Amaurosis fugax: the results of arteriography in 59 patients. Stroke. 1983;14(5): 742-744.

34. Park MS, Kim JT, Lee KR, et al. Recurrent transient monocular blindness with ophthalmic artery stenosis. Eur Neurol. 2008;59(3-4):202-204.

35. Choi SY, Moon HJ, Huh YE, et al. Recurrent transient monocular blindness from stenotic central retinal artery. J Clin Neurosci. 2013; 20(11):1603-1605.

36. Glueck CJ, Hutchins RK, Jurantee J, Khan Z, Wang P. Thrombophilia and retinal vascular occlusion. Clin Ophthalmol. 2012;6:1377-1384.

37. Schockman S, Glueck CJ, Hutchins RK, Patel J, Shah P, Wang P. Diagnostic ramifications of ocular vascular occlusion as a first thrombotic event associated with factor V Leiden and prothrombin gene heterozygosity. Clin Ophthalmol. 2015;9:591-600.

38. Glueck CJ, Goldenberg N, Bell H, Golnik K, Wang P. Amaurosis fugax: associations with heritable thrombophilia. Clin Appl Thromb Hemost. 2005;11(3):235-241. 
39. Kalaria C, Kittner S. The therapeutic value of laboratory testing for hypercoagulable states in secondary stroke prevention. Neurol Clin. 2015;33(2):501-513.

40. Pahus SH, Hansen AT, Hvas AM. Thrombophilia testing in young patients with ischemic stroke. Thromb Res. 2015: S0049-3848(15)30182-1. doi:10.1016/j.thromres.2015.11.006.

41. Headache Classification Committee of the International Headache Society. Classification and diagnostic criteria for headache disorders, cranial neuralgias, and facial pain. Cephalalgia. 1988;8 (Suppl 7): 1-96.

42. Headache Classification Subcommittee of the International Headache Society. The International Classification of Headache Disorders, 2nd edition. Cephalalgia. 2004;24 (Suppl 1):1-160.

43. Evans RW, Grosberg BM. Retinal migraine: migraine associated with monocular visual symptoms. Headache. 2008;48(1):142-145.

44. Hill DL, Daroff RB, Ducros A, Newman NJ, Biousse V. Most cases labeled as "retinal migraine" are not migraine. JNeuroophthalmol. 2007; 27(1):3-8.

45. Flammer J, Pache M, Resink T. Vasospasm, its role in the pathogenesis of diseases with particular reference to the eye. Prog Retin Eye Res. 2001;20(3):319-349.

46. Shim DH, Cha JK, Kang MJ, Choi JH, Nah HW. Vasospastic amaurosis fugax diagnosed by cerebral angiography. J Stroke Cerebrovasc Dis. 2015;24(11):e323-e325.

47. Johansson EP, Arnerlöv C, Wester P. Risk of recurrent stroke before carotid endarterectomy: the ANSYSCAP study. Int J Stroke. 2013;8(4): 220-227.

48. Grosberg BM, Solomon S, Friedman DI, Lipton RB. Retinal migraine reappraised. Cephalalgia. 2006;26(11):1275-1286.

49. Pitkänen H, Saarela V. Vasospastic transient monocular visual loss: effect of treatment with different doses of nifedipine. J Neuroophthalmol. 2014;34(4):386-388.
50. Kowacs PA, Utiumi MA, Piovesan EJ. The visual system in migraine: from the bench side to the office. Headache. 2015;55 Suppl 1:84-98.

51. Singhi P, Saini AG, Sankhyan N. Amaurosis fugax caused by neurocysticercosis. Pediatr Infect Dis J. 2014;33(4):427.

52. Horwitz NH, Wener L. Temporary cortical blindness following angiography. J Neurosurg. 1974;40(5):583-586.

53. Lo LW, Chan HF, Ma KF, Cheng LF, Chan TK. Transient cortical blindness following vertebral angiography: a case report. Neurointervention. 2015;10(1):39-42.

54. Rozen TD. Migraine with binocular blindness: a clinic-based study Headache. 2011;51(10):1529-1536.

55. Paul NL, Simoni M, Rothwell PM; Oxford Vascular Study. Transient isolated brainstem symptoms preceding posterior circulation stroke: a population-based study. Lancet Neurol. 2013;12(1):65-1.

56. Easton JD, Saver JL, Albers GW, et al. Definition and evaluation of transient ischemic attack: a scientific statement for healthcare professionals from the American Heart Association/American Stroke Association Stroke Council; Council on Cardiovascular Surgery and Anesthesia; Council on Cardiovascular Radiology and Intervention; Council on Cardiovascular Nursing; and the Interdisciplinary Council on Peripheral Vascular Disease. Stroke. 2009;40(6):2276-2293.

57. Johnston SC, Nguyen-Huynh MN, Schwarz ME, et al. National Stroke Association guidelines for the management of transient ischemic attacks. Ann Neurol. 2006;60(3):301-313.

58. Helenius J, Arsava EM, Goldstein JN, et al. Concurrent acute brain infarcts in patients with monocular visual loss. Ann Neurol. 2012;72(2): 286-293.

59. Lauda F, Neugebauer H, Reiber L, Jüttler E. Acute Silent Brain Infarction in Monocular Visual Loss of Ischemic Origin. Cerebrovasc Dis. 2015; 40(3-4):151-156.
Clinical Ophthalmology

\section{Publish your work in this journal}

Clinical Ophthalmology is an international, peer-reviewed journal covering all subspecialties within ophthalmology. Key topics include: Optometry; Visual science; Pharmacology and drug therapy in eye diseases; Basic Sciences; Primary and Secondary eye care; Patient Safety and Quality of Care Improvements. This journal is indexed on

Submit your manuscript here: http://www.dovepress.com/clinical-ophthalmology-journal

\section{Dovepress}

PubMed Central and CAS, and is the official journal of The Society of Clinical Ophthalmology (SCO). The manuscript management system is completely online and includes a very quick and fair peer-review system, which is all easy to use. Visit http://www.dovepress.com/ testimonials.php to read real quotes from published authors. 